\title{
QT luzearen sindromea, bat-bateko heriotzaren atzean
}

\author{
Long QT syndrome, behind sudden death \\ Beñat de Alba Iriarte ${ }^{1}$ \\ ${ }^{1}$ Donostia Unibertsitate Ospitaleko Analisi Klinikoen Zerbitzua \\ benat.dealbairiarte@osakidetza.eus
}

\section{Laburpena}

QT luzearen sindromea kanalopatia larria da. 2.500 pertsonatik bati eragiten dio, bereziki gazteei. Bihotzeko bentrikuluen zelulen birpolarizazio-fasearen luzatzea du ezaugarri eta, ondorioz, elektrokardiograman QT tartearen luzapena ageri da. Horrek gaixoei sinkopea eta fibrilazio bentrikularrak eragindako bat-bateko heriotza izateko arriskua handitzen die.

Sindrome hau kirolarien bat-bateko heriotzaren arrazoietako bat da. Gaixo sintomatikoen edo elektrokardiograma patologikoa dutenen maneiua aski ezaguna da, baina azken urteotan gaixotasun hau eragiten duten hainbat mutazio genetiko deskribatu dira, oraindik adierazpen fenotipikorik ez duten zenbait pertsonatan. Gero eta hedatuago dagoen proba genetikoen erabilerak mutazio mota horien eramaile asko diagnostikatzea erraztu du.

Gako-hitzak: bat-bateko heriotza, bihotza, sindromea, sinkopea, torsades de pointes, QT luzea

\section{Abstract}

Long QT syndrome is a channelopathy that affects approximately one in 2,500 people, mainly young people. It is characterized by a prolongation of ventricular repolarization that is manifested by an increase in the $Q T$ interval on the electrocardiogram. This exposes patients to syncope and sudden death from ventricular fibrillation.

This syndrome is one of the possible causes of sudden death in sports. The management of symptomatic patients or those with electrocardiographic expression is known. However, in recent years, genetic mutations have been described, predisposing people to suffer from this pathology even without phenotypic manifestation. The increasingly widespread application of genetic testing has allowed discovering many carriers of this type of mutations.

Keywords: sudden death, heart, syndrome, syncope, torsades de pointes, long QT

\section{Deskribapen orokorra}

QT luzearen sindromea (Long QT Syndrome, LQTS) $(1,2)$ taupada azkar eta kaotikoak eragin ditzakeen bihotz-erritmoaren nahasmendua da, eta taupada horiek bat-bateko zorabioak edo konbultsioak eragin ditzakete. Kasu batzuetan, bihotzak modu erratikoan egin ditzake taupadak denbora luzez, bat-bateko heriotza eragin arte.

Litekeena da QT luzearen sindromearekin jaiotzeko arriskua handiagotzen duen mutazio genetiko bat izatea (herentziazko LQTSa edo familiarra). Gainera, sendagai batzuek, elektrolitoen gorabeherek eta zenbait gaixotasunek QT luzearen sindromea eragin dezakete (hartutako LQTSa).

Tratamendua du: bihotz-erritmo erratikoa prebenitzeko medikamentuak, kirurgia, gailu bat ezartzea eta sindrome hori eragin lezaketen zenbait sendagai saihestea. 
Tratamenduaren ondoren, gaixotasun honekin bizi eta haz daiteke, baita, beharbada, jolaskiroletan aktibo bizi ere, eta, kasu bakanetan, lehia-kiroletan ere bai.

\section{Sintomak}

LQTSa duten pertsona askok ez dute zeinurik edo sintomarik $(1,2)$.

Honako arrazoi hauengatik ohar gaitezke gaixotasunaz:

- Erlaziorik ez duen arrazoi batengatik egindako elektrokardiograma baten emaitzagatik.

- LQTSaren familia-aurrekariengatik.

- Analisi genetikoen emaitzengatik.

LQTSaren zeinuak eta sintomak dituzten pertsonen kasuan, hauek dira arruntenak:

- Zorabioak: zeinu ohikoena da. LQTSak eragindako zorabioak (sinkopeak) bihotzak aldi mugatu batez dituen taupada erratikoen ondorioz gertatzen dira. Zorabio horiek hunkidura-, haserre- edo beldur-une batean edo kirola egitean gerta daitezke.

- Konbultsioak: bihotzak modu erratikoan taupadaka jarraitzen badu, garunak ez du behar adina oxigeno jasoko eta konbultsioak gertatuko dira.

- Bat-bateko heriotza: Normalean, bihotza bere erritmo normalera itzultzen da. Hori berez gertatzen ez bada edo erritmoa normalizatzeko kanpoko desfibriladore bat erabiltzen ez bada, bat-bateko heriotza gerta daiteke.

Familiari lotutako LQTS zeinuak eta sintomak fetuan, jaio ondorengo lehen asteetan edo hilabeteetan, helduaroan edo zahartzaroan identifika daitezke, edo gerta liteke inoiz ez antzematea. Loaldian edo esnatzeko unean ere gerta daitezke. Pertsona gehienek 30-40 urterekin izaten dute gaixotasunaren lehen agerraldia.

\section{Kausak}

LQTSa bihotz-erritmo irregular eta larriak (arritmiak) eragin ditzakeen nahasmendua da $(1,2)$.

Normalean, bihotzak odola zirkularazten du gorputz osoan taupada bakoitzarekin. Odola ponpatzeko, bihotzaren barrunbeak uzkurtu eta erlaxatu egiten dira. Ekintza horiek bihotzean garraiatzen diren eta taupadak sortzen dituzten bulkada elektrikoen bidez kontrolatzen dira. Taupada bakoitzaren ondoren, bihotzaren sistema elektrikoa hurrengo taupadarako prestatzeko kargatzen da.

LQTSan, bihotz-giharrak ohi baino denbora gehiago behar du taupada batetik hurrengora arte birkargatzeko. Elektrokardiograman ikusi ohi den alterazio elektriko horri "QT luzea" deitzen zaio.

\section{QT luzearen familia-sindromea}

Orain arte, 700 mutazio baino gehiago identifikatu dira LQTSarekin lotutako 13 genetan, eta horietatik \% 75 inguru 3 genetan daude: KCNQ1 (1. motako LQTSa) eta KCNH2 (2. motako LQTSa), zeinek potasio-kanalei eragiten baitiete, eta SCN5A (3. motako LQTS), zeinak sodiokanalak kodetzen baititu. Hain ohikoak ez diren beste geneetako mutazioek kasuen ehuneko txiki bat osatzen dute.

Jaiotzean LQTSa duten pertsonen \% 20 inguruk emaitza negatiboa ematen du proba genetikoan. Bestalde, LQTSa genetikoki ezarria duten familietan, proba genetikoan emaitza positiboa duten senideen \% 10-33k QT tarte normala du.

Familiari lotutako bi LQTS mota daude: 
- Romano-Warden sindromea. Ohikoena da, eta gurasoetako baten aldaera genetiko bakarra heredatu duten pertsonetan gertatzen da.

- Jervell eta Lange-Nielsenen sindromea. Ez da hain ohikoa, adinez goiz agertzen da eta larriagoa da. Sindrome honetan, haurrek bi gurasoen aldaera genetikoak heredatzen dituzte. LQTSa dute eta jaiotzez gorrak dira.

\section{Hartutako QT luzearen sindromea}

Zenbait medikamentuk, anomalia elektrolitikoek edo gaixotasunek eragin dezakete. 100 medikamentuk baino gehiagok - horietako asko arruntak dira- QT tartea luza dezakete pertsona osasuntsuetan, eta hartutako LQTSa eragin dezakete; medikamentu horien artean daude, besteak beste, antiarritmikoak, antibiotikoak, antipsikotikoak eta antihistaminikoak.

\section{Arrisku-faktoreak}

Familiari lotutako LQTSa edo hartutakoa izateko arrisku handiena izan dezaketen pertsonak hauek dira (2):

- Itxuraz arrazoirik gabe konortea galtzen duten haur, nerabe eta heldu gazteak, itotzetik hurbil dauden egoerak edo arrazoi ezagunik gabeko bestelako istripu batzuk, arrazoi jakinik gabeko konbultsioak edo bihotz-gelditzearen aurrekariak dituztenak.

- $\quad$ Diagnostikatutako LQTSa duten pertsonen lehen mailako senideak.

- QT tarte luzea sortzen duten sendagaiak hartzen dituzten pertsonak.

- Odolean potasio-, magnesio- edo kaltzio-maila baxuak dituzten pertsonak, hala nola nerbio-anorexia deritzon elikadura-nahasmendua dutenak.

Askotan, LQTS familiarra ez da diagnostikatzen edo gaizki diagnostikatzen da, konbultsionahasmendu gisa (epilepsia, adibidez). Hala ere, haurren eta heldu gazteen heriotza batzuen erantzule izan daiteke LQTSa.

\section{Konplikazioak}

Gehienetan, sindrome hau duten pertsonen QT tarte luzeek ez dute inoiz arazorik sortzen. Haatik, estres fisiko edo emozionalak QT tartea luzatzera bultza dezake horretarako joera duen bihotz bat. Horren ondorioz, bihotz-erritmoa deskontrolatu eta bizitza arriskuan jar dezaketen arritmiak sor daitezke, hala nola:

- Torsades de pointes (takikardia bentrikular bihurrikatua) (2). Arritmia mota honetan, bentrikuluek modu azkar eta kaotikoan egiten dituzte taupadak, eta beraz, elektrokardiogramaren monitoreko uhinek okerrak dirudite. Bihotzak odol gutxiago ponpatzen du, horregatik garunera odol gutxiago iristen da eta bat-bateko konortegalera gertatzen da, oro har, aldez aurretiko sintomarik gabe.

- Bentrikuluaren fibrilazioa. Nahasmendu honetan bentrikuluek taupadak hain azkar egiten dituztenez, bihotza dardarka hasten da eta ez du odola ponpatzen. Bihotzari talka egiten ez bazaio, desfibriladore baten bidez erritmo normalera itzul dadin, fibrilazio bentrikularrak garuneko kaltea eta bat-bateko heriotza eragin ditzake.

Gaur egun jakina da LQTSa itxuraz osasuntsuak ziren gazteen bat-bateko heriotza-kasu batzuen arrazoia izan zela.

\section{Diagnostikoa}

LQTSa diagnostikatzeko, medikuak sintomak ebaluatzen ditu, historia klinikoa eta familiaaurrekariak aztertzen ditu, eta miaketa fisikoa egiten du (3).

Diagnostikoa baieztatzeko, hainbat proba egin daitezke $(4,5)$ :

- Elektrokardiograma.

- Holter azterketa.

- Estres-proba farmakologikoa adrenalinarekin.

- Analisi genetikoak. 
LQTSaren kausa genetikoa duen analisi genetiko baten bidez zehazten bada, azterketa egitea gomenda diezaieke medikuak gaixoaren senitartekoei ere, mutazio genetiko bera heredatu ote zuten zehazteko.

\section{Tratamendua}

Tratamenduaren helburuak QT luzea duen bihotzak kontrolik gabeko taupadak egitea edo batbateko heriotza saihestea dira (1).

LQTS familiarraren tratamenduak hainbat neurri ditu:

- Sendagaiak: beta-blokeatzaileak; ez dira paziente guztientzat egokiak, kasuaren eta sindrome motaren arabera baizik. Estimulazio sinpatiko bortitz baten (esfortzua, beldurra, etab.) ondorioz takikardia bentrikularra pairatzen duten mutazio jakin batzuk dituzten pazienteetan dira eraginkorrak; beste mutazio batzuk dituzten pertsonetan takikardia bentrikularra egoera lasaietan agertzen da eta beta-blokeatzaileak kaltegarriak izan daitezke.

- Prozedura kirurgikoak: bihotzeko ezkerreko nerbio sinpatikoa kentzeko kirurgia, taupada-markagailua edo barne-kardiobertsio elektrikoa.

Hartutako LQTSaren kasuan, sendagai jakin batzuen ondoriozkoa bada, gaixotasuna eragin duten medikamentuak hartzeari utzi behar zaio, eta beste batzuengatik aldatu.

\section{Prebentzioa}

Baliteke pertsona batzuek, batez ere denbora luzean gaixotasunaren zeinurik edo sintomarik izan ez duten LQTSdun adineko helduek, prebentzio-neurriak hartu baino behar ez izatea. Oro har, paziente horiek esfortzu handirik ez egiteko aholkua dute. Agian ez da beharrezkoa kirola egiteari uztea, baina ariketa nekagarria egitea arriskutsua izan daiteke eta ez da gomendagarria LQTSa duten pertsona batzuentzat. Hala ere, beste pertsona batzuek konplikazio-arrisku txikiagoa izan dezakete eta lehia-kiroletan parte hartzeko oniritzia dute.

Azken urteotan, hainbat mutazio genetiko erlazionatu dira LQTSarekin, eta mutazio horiek gaixotasunaren adierazpen klinikorik eta elektrokardiografikorik gabeko pazienteek izan ditzakete. Larriak izan daitezkeen bihotzeko patologien azterketa genetikoak eragin berezia du kirol-medikuntzan, eta oso tresna garrantzitsua izan daiteke gaixotasun kardiobaskularren baheketan. Bere aplikazioari esker, horrelako mutazioak dituzten paziente asko identifikatu dira, eta azterketa genetikoa lehen mailako senideei zabaldu zaie, gaixotasuna eta sintomak prebenitzeko.

\section{Erreferentzia bibliografikoak}

1. Goldenberg I, Moss A. Long QT Syndrome [Internet]. J Am Coll Cardiol. 2008 [Kontsulta: 2020-12-05]; 51:2291-2300. Eskuragarri: https://doi.org/10.1016/j.jacc.2008.02.068

2. Viskin S. Long QT syndromes and torsade de pointes [Internet]. Lancet. 1999 [Kontsulta: 2020-12-05]; 354:1625-1633. Eskuragarri: https://doi.org/10.1016/S0140-6736(99)02107-8

3. Schwartz P, Moss A, Vincent M, Crampton RS. Diagnostic criteria for the long QT syndrome. An update [Internet]. Circulation. 1993 [Kontsulta: 2020-12-05]; 88:782-796. Eskuragarri: https://doi.org/10.1161/01.cir.88.2.782

4. Shimizu W, Noda T, Takaki H, Nagaya N, Satomi K, Kurita T, Suyama K, Aihara N, Sunagawa K, Echigo S, Miyamoto Y, Yoshimasa Y, Nakamura K, Ohe T, Towbin JA, Priori SG, Kamakura S. Diagnostic value of epinephrine test for genotyping LQT1, LQT2, and LQT3 forms of congenital long QT syndrome [Internet]. Hearth Rhythm. 2004 [Kontsulta: 2020-12-05]; 1:276-283. Eskuragarri: https://doi.org/10.1016/j.hrthm.2004.04.021

5. Medeiros-Domingo A, Iturralde Torres $P$, Ackerman MJ. Clínica y genética en el síndrome de QT largo [Internet]. Rev Esp Cardiol; 2007 [Kontsulta: 2020-12-05]; 60:739-752. Eskuragarri: https://doi.org/10.1016/S1885-5857(08)60010-9 